Journal of Zhejiang University-SCIENCE A (Applied Physics \& Engineering)

ISSN 1673-565X (Print); ISSN 1862-1775 (Online)

www.jzus.zju.edu.cn; link.springer.com

E-mail: jzus_a@zju.edu.cn

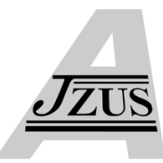

Editorial:

\title{
Noise and vibration from transportation
}

Georges KOUROUSSIS ${ }^{\dagger 1}$, Sheng-yang ZHU², Konstantinos VOGIATZIS $^{3}$

${ }^{1}$ Department of Theoretical Mechanics, Dynamics and Vibrations, University of Mons, Mons 7000, Belgium

${ }^{2}$ Train and Track Research Institute, State Key Laboratory of Traction Power, Southwest Jiaotong University, Chengdu 610031, China

${ }^{3}$ Laboratory of Transportation Environmental Acoustics (LTEA),

University of Thessaly, Volos 8334, Greece

†E-mail: georges.kouroussis@umons.ac.be

https://doi.org/10.1631/jzus.A20NVT01

Nowadays, railway ranks as an environmentally friendly and sustainable form of transport associated with a continuously expanding network. This success, often considered as the second "golden age" of rail, induces a vision of trains that should be quiet and vibrationless (Connolly et al., 2016; Vogiatzis and Kouroussis, 2017b). However, numerous environmental technical challenges are associated with railway infrastructure, including the assessment of urban railway vibrations and noise (Vogiatzis and Kouroussis, 2017a).

Prediction models are widely used at present to understand the nature of railway ground waves and their associated characteristics. Simulating excitation is of major concern and fixes the choice of a proper numerical model. Fig. 1 indicates the major sources of vibration originating from the passing of trains:

1. Moving load effect

This effect has been studied for several years, leading to many analytical and numerical prediction models. The associated problem is to determine the vibration level when a (constant) load is moving along a straight line on the surface of a half-space and generally at constant speed: the analogy with a moving railway vehicle is obvious. Specific situations can

(ib) ORCID: Georges KOUROUSSIS, https://orcid.org/0000-00029233-1354; Sheng-yang ZHU, https://orcid.org/0000-0002-8281-8361; Konstantinos VOGIATZIS, https://orcid.org/0000-0003-0385-9147 (C) Zhejiang University Press 2021 be studied, such as the super-critical phenomenon appearing when a vehicle moves at a speed greater than that of the wave propagating into the soil (Krylov and Ferguson, 1994).

2. Distributed track unevenness

Rail and wheel surface geometries are not perfect. Unevenness makes contact between wheels and rails less than perfect and generates a dynamic excitation directly observable in the evaluation of railway-generated ground vibrations. Distributed rail unevenness data are often in the form of spectra (power spectral density) as a function of the spatial frequency (number of cycles per unit of length) with a specific shape, often defined in railway standards (Garg and Dukkipati, 1984).

3. Localized defects on the rail surface

Singular defects such as rail joints, switches, and crossings are a significant source of dynamic excitation on railway tracks. They appear mainly in urban environments, rather than in high-speed lines, and represent the main contributor of railway-induced ground vibrations, even at low vehicle speeds (Kouroussis et al., 2015). Noise generated by the passing of wheels over localized defects is also important.

4. Localized defects on the wheel surface

Typically, a flat spot or 'wheel flat' occurs when a wheelset is dragged along the rail due to emergency braking or during slip and slide conditions. In some cases, the dynamic effect of a wheel flat is of the same order of magnitude as a localized defect on a rail, with similar levels of ground vibration, in addition to the repetitiveness that occurs at one or more positions on the wheel circumference (Alexandrou et al., 2016).

Historically, the field of railway noise was studied before problems of railway vibration. Compared to aerodynamic noise, rolling noise and traction noise are dominant at low speed. The mechanisms of such noise are well understood by researchers in this field. In urban conditions, the dominant source of noise remains the rolling noise, generated by the 


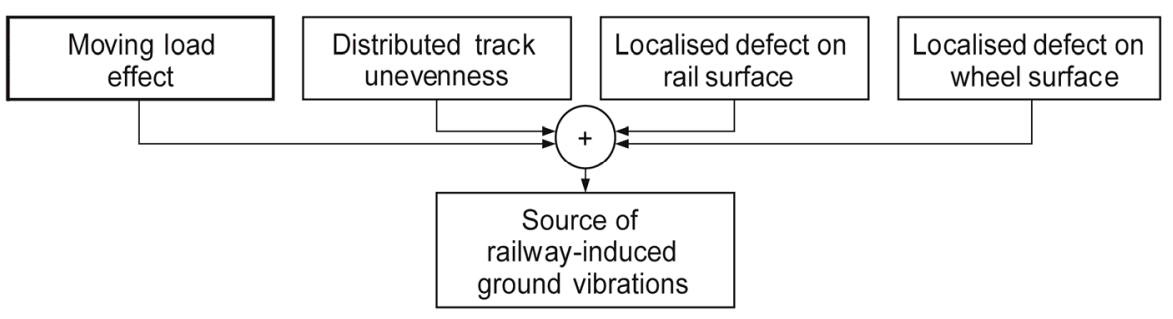

Fig. 1 Cumulative effect of different sources of railway-induced ground vibrations

interaction of rotating wheels and the rail. Vibroacoustic studies can be helpful to elucidate the generation mechanisms and reduce railway noise (Thompson, 2009).

Recently, much research has been devoted to the very complex theme of railway induced ground vibration and noise. The proposed topic of this special issue, covered by four papers, is the broad issue of the generation and propagation of sound and ground borne vibration from rail transport. Rail induced vibration has gained more attention in recent years. In this special issue, primary scientists on the leading edge in this field were invited to share their recent findings and expertise.

Auersch and Said (2021) present a comparison of the dynamic effects of ballasted and slab tracks through a mixed experimental/numerical study. This is an extended version of their conference paper (Auersch and Said, 2019), including additional results related to ballasted tracks. Artificial and real condition excitations were used to extract the track resonances and to analyze the stiffness of track elements, including all components of slab and ballast tracks. Track deflections and transfer functions were analyzed for various track and soil configurations. These observations were confirmed by numerical solutions, using the wavenumber domain method for the calculation of ballast and slab tracks. This hybrid analysis has some advantages, especially providing the possibility to corroborate the primary conclusions. In addition, the results presented provide a large database for transport sector specialists.

Lyratzakis et al. (2021) focus on high-speed trains and their effect on the neighborhood, with possible mitigation measures as a highlight. After a concise and efficient analysis of the possible solution (technically and economically speaking), they suggest the use of expanded polystyrene geofoam blocks as embankment material. It is well known that embankments play an important role in vibration propagation and attenuation. As waveguides trapping energy within them, their efficiency depends on the embankment material (Olivier et al., 2016). Hence, a numerical analysis was conducted using the finite element method for modelling the soil wave propagation, previously validated by Lyratzakis et al. (2020). The main geometrical parameters (height, slope) were analyzed to quantify the isolation properties of such blocks.

Zhang et al. (2021) studied the noise generated by trains running on an elevated railway. From a field test of an elevated metro line, the propagation and attenuation of emitted noise was analyzed in the time domain and the frequency domain (linear and one-third octave analysis, respectively). The noise beside a box girder bridge was deduced as a function of the energy and the spatial distribution. To evaluate the impact of bridge structure on noise, a structural model is proposed, based on a train/track/bridge model previously developed (Zhang et al., 2019). This approach offers a way to calculate the corresponding acoustic radiation, after having validated the proposed model. Using time and frequency domain analysis methods, the impact of the bridge structure on the bridge-side environmental noise was analyzed. Finally, the Doppler effect due to the moving source represented by a train was studied. It was proved that such an effect plays an essential role in the measurement analysis.

Zhao et al. (2021) devoted their research to floating slab tracks. Floating slab tracks represent a globally recognized mitigation solution for urban conditions (Vogiatzis and Kouroussis, 2015). However, an undesirable effect of this in terms of track design appears at low frequencies, at which vibration amplification can occur. To overcome this deficiency, 
the authors suggest a novel mitigation measure based on the theory of quasi-zero-stiffness vibration isolators. After a detailed description of such systems, they establish a compound system involving railway vehicles, a floating slab track, and vibration isolators, based on the formalism proposed by Zhai and Sun (1994). In this way, they prove theoretically the improvement in low-frequency vibration reduction made possible by quasi-zero-stiffness vibration isolators. The next step should be the validation of this novel concept.

From these papers, there appears to be a need for harmonization of metrics used to assess structural vibration with respect to comfort and structural damage, similar to that proposed for airborne noise (Thompson et al., 2019). Indeed, recent research shows that national and international standards and recommendations provide different means of evaluating ground vibration based on specific motion metrics (Kouroussis et al., 2014). Numerical models offer a way to evaluate these structural vibrations and possible solutions to mitigate them, before testing physically (Kouroussis et al., 2019; Yang et al., 2019). At the same time, it is important to pay attention to the life-cycle performance of these new mitigation methods (Kaewunruen and Martin, 2018).

We hope that the most up-to-date views expressed in the four papers shared in this special issue demonstrate real potential for improving the urban environment. We also hope these research articles will promote discussion and provide benefits for journal readers.

\section{Conflict of interest}

Georges KOUROUSSIS, Sheng-yang ZHU, and Konstantinos VOGIATZIS declare that they have no conflict of interest.

\section{References}

Alexandrou G, Kouroussis G, Verlinden O, 2016. A comprehensive prediction model for vehicle/track/soil dynamic response due to wheel flats. Proceedings of the Institution of Mechanical Engineers, Part F: Journal of Rail and Rapid Transit, 230(4):1088-1104. https://doi.org/10.1177/0954409715576015

Auersch L, Said S, 2019. Measurement of slab track behaviour at different sites. Proceedings of the 26th International Congress on Sound and Vibration.

Auersch L, Said S, 2021. Dynamic track-soil interactioncalculations and measurements of slab and ballast tracks. Journal of Zhejiang University-SCIENCE A (Applied
Physics \& Engineering), 22(1):21-36.

https://doi.org/10.1631/jzus.A1900651

Connolly DP, Marecki G, Kouroussis G, et al., 2016. The growth of railway ground vibration problems - a review. Science of the Total Environment, 568:1276-1282. https://doi.org/10.1016/j.scitotenv.2015.09.101

Garg VK, Dukkipati RV, 1984. Dynamics of Railway Vehicle Systems. Academic Press, Toronto, Canada. https://doi.org/10.1016/B978-0-12-275950-5.X5001-9

Kaewunruen S, Martin V, 2018. Life cycle assessment of railway ground-borne noise and vibration mitigation methods using geosynthetics, metamaterials and ground improvement. Sustainability, 10(10):3753. https://doi.org/10.3390/su10103753

Kouroussis G, Conti C, Verlinden O, 2014. Building vibrations induced by human activities: a benchmark of existing standards. Mechanics \& Industry, 15(5):345-353. https://doi.org/10.1051/meca/2014041

Kouroussis G, Connolly DP, Alexandrou G, et al., 2015. The effect of railway local irregularities on ground vibration. Transportation Research Part D: Transport and Environment, 39:17-30. https://doi.org/10.1016/j.trd.2015.06.001

Kouroussis G, Zhu SY, Olivier B, et al., 2019. Urban railway ground vibrations induced by localized defects: using dynamic vibration absorbers as amitigation solution. Journal of Zhejiang University-SCIENCE A (Applied Physics \& Engineering), 20(2):83-97. https://doi.org/10.1631/jzus.A1800651

Krylov V, Ferguson C, 1994. Calculation of low-frequency ground vibrations from railway trains. Applied Acoustics, 42(3):199-213. https://doi.org/10.1016/0003-682X(94)90109-0

Lyratzakis A, Tsompanakis Y, Psarropoulos PN, 2020. Efficient mitigation of high-speed trains induced vibrations of railway embankments using expanded polystyrene blocks. Transportation Geotechnics, 22:100312. https://doi.org/10.1016/j.trgeo.2019.100312

Lyratzakis A, Tsompanakis Y, Psarropoulos PN, 2021. Mitigation of high-speed trains vibrations by expanded polystyrene blocks in railway embankments. Journal of Zhejiang University-SCIENCE A (Applied Physics \& Engineering), 22(1):6-20. https://doi.org/10.1631/jzus.A1900680

Olivier B, Connolly DP, Costa PA, et al., 2016. The effect of embankment on high speed rail ground vibrations. International Journal of Rail Transportation, 4(4):229-246. https://doi.org/10.1080/23248378.2016.1220844

Thompson D, 2009. Railway Noise and Vibration: Mechanisms, Modelling and Means of Control. Elsevier, Oxford, UK.

Thompson DJ, Kouroussis G, Ntotsios E, 2019. Modelling, simulation and evaluation of ground vibration caused by rail vehicles. Vehicle System Dynamics, 57(7):936-983. https://doi.org/10.1080/00423114.2019.1602274

Vogiatzis K, Kouroussis G, 2015. Prediction and efficient 
control of vibration mitigation using floating slabs: practical application at Athens metro lines 2 and 3. International Journal of Rail Transportation, 3(4):215-232. https://doi.org/10.1080/23248378.2015.1076622

Vogiatzis K, Kouroussis G, 2017a. Airborne and ground borne noise and vibration from urban rail transit systems. In: Yaghoubi H (Ed.), Urban Transport Systems. InTechOpen, p.61-87.

Vogiatzis K, Kouroussis G, 2017b. Environmental groundborne noise and vibration from urban light rail transportation during construction and operation. Current Pollution Reports, 3(2):162-173.

https://doi.org/10.1007/s40726-017-0059-3

Yang JJ, Zhu SY, Zhai WM, et al., 2019. Prediction and mitigation of train-induced vibrations of large-scale building constructed on subway tunnel. Science of the Total Environment, 668:485-499. https://doi.org/10.1016/j.scitotenv.2019.02.397

Zhai WM, Sun X, 1994. A detailed model for investigating vertical interaction between railway vehicle and track.
Vehicle System Dynamics, 23(S1):603-615.

https://doi.org/10.1080/00423119308969544

Zhang YF, Li J, Chen ZW, et al., 2019. Dynamic analysis of metro vehicle traveling on a high-pier viaduct under crosswind in Chongqing. Wind and Structures, 29(5): 299-312.

https://doi.org/10.12989/was.2019.29.5.299

Zhang YF, Li L, Lei ZY, et al., 2021. Environmental noise beside an elevated box girder bridge for urban rail transit. Journal of Zhejiang University-SCIENCE A (Applied Physics \& Engineering), 22(1):53-69. https://doi.org/10.1631/jzus.A1900678

Zhao ZM, Wei K, Ren JJ, et al., 2021. Vibration response analysis of floating slab track supported by nonlinear quasi-zero-stiffness vibration isolators. Journal of Zhejiang University-SCIENCE A (Applied Physics \& Engineering), 22(1):37-52.

https://doi.org/10.1631/jzus.A2000040

\section{Introducing Guest Editor-in-Chief and Guest Editors: \\ Guest Editor-in-Chief}

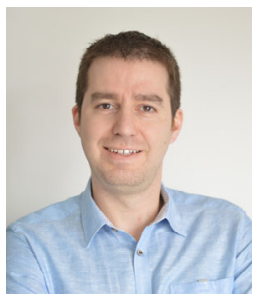

Prof. Georges KOUROUSSIS is an editorial board member of Journal of Zhejiang University-SCIENCE A (Applied Physics \& Engineering) since 2018. He is an Associate Professor in the Department of Mechanical Engineering at the University of Mons, Belgium. He graduated from the Faculty of Engineering of Mons with a magna cum laude honours degree in mechanical engineering in 2002, and started to work as a research and teaching assistant at the University of Mons. He obtained his PhD from the University of Mons in 2009. He was an invited researcher in the National Technical University of Athens (Greece) before being appointed to the academic staff in the University of Mons. Since 2010 he has been Senior Research Assistant, Senior Lecturer, and Associate Professor. His research interests are in the environmental impact of vibrations induced by the railway traffic, the simulation of multibody models, signal processing for effective vibration analysis, the soil-structure interaction, and the modal analysis.

Prof. KOUROUSSIS is an Associate Editor of several international journals (Shock and Vibration, Transport, and Railway Engineering Science). He also serves in the editorial board of International Journal of Rail Transportation, Urban Rail Transit, and MDPI/Sustainability. He was also Director of the International Institute of Acoustics and Vibration (IIAV) for the period 2016-2020. He has published 70+ SCI journal articles and 100+ conference papers.

\section{Guest Editors}

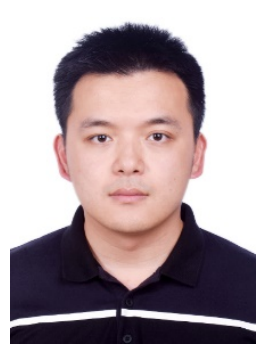

Dr. Sheng-yang ZHU is currently an Associate Professor at Train and Track Research Institute affiliated to State Key Laboratory of Traction Power, Southwest Jiaotong University (SWJTU) in China. He graduated from SWJTU with PhD degree in Rail Transportation Engineering in 2015. He had a research experience in Rice University (USA) as an award holder from China Scholarship Council for 18 months since 2012. His research interests include a wide range of aspects of train-track interaction as well as track vibration control, track damage mechanism, and structural health monitoring.

Prof. ZHU is a recipient of several academic awards including the First-Class Award in Natural Science of the Ministry of Education in China (ranks No. 2), the Young Elite Scientist Award of China Association for Science and Technology, and the Young Eagle Scholar Award of SWJTU. He is an editorial board member of the international journal Transport, and the co-chairman of the New Rail Transit Committee of the World Transport Convention.

Prof. ZHU is the principal investigator of three projects of National Natural Science Foundation of China, and the main investigator of National Basic Research Program (973 Program) of China. He has published more than 60 journal papers, including about $30 \mathrm{SCI}$-indexed papers and two ESI highly cited papers, and has delivered several keynote or invited presentations in international conferences and seminars. He has co-authored some chapters for two international authoritative monographs. 


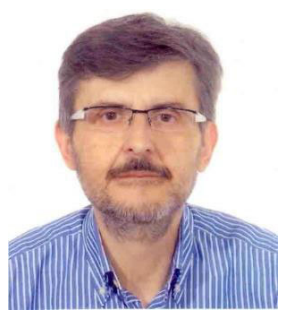

Dr. Konstantinos VOGIATZIS is a Professor of the Department of Civil Engineering in the scientific object of "Transport Noise in Environmental and Spatial Planning," University of Thessaly, Greece. His research interests include planning, management and protection from urban environmental noise and air pollution from the construction and operation of transport networks with a focus on airborne noise, ground-borne noise and vibrations and fixed track transportation (Metro, Tram \& High speed rail networks), air transports and intercity, exurban \& suburban road transport systems in combination with their integrated environmental and spatial management. He has published more than 300 articles in scientific journals and conferences, and he is a Scientific Director and Coordinator in a number of research programs. $\mathrm{He}$ is the Founder and Head of the Laboratory of Transportation Environmental Acoustics (LTEA). Prof. VOGIATZIS is a Former Director of MoB International Institute of Acoustics and Vibration and Associate Editor of International Journal of Acoustics and Vibration. He is also an editorial board member of Noise Mapping and The Open Transportation Journal and Guest Editor for several international journals. 